\title{
Mechanical Properties and Acoustic Emission Properties of Rocks with Different Transverse Scales
}

\author{
Xi Yan, ${ }^{1}$ Li Jun, ${ }^{1}$ Liu Gonghui, ${ }^{1,2}$ and Guo Xueli ${ }^{1}$ \\ ${ }^{1}$ China University of Petroleum-Beijing, Beijing 102249, China \\ ${ }^{2}$ Beijing University of Technology, Beijing 100022, China \\ Correspondence should be addressed to Xi Yan; 315791585@qq.com
}

Received 24 May 2017; Revised 4 September 2017; Accepted 10 September 2017; Published 11 October 2017

Academic Editor: Salvatore Russo

Copyright (C) 2017 Xi Yan et al. This is an open access article distributed under the Creative Commons Attribution License, which permits unrestricted use, distribution, and reproduction in any medium, provided the original work is properly cited.

\begin{abstract}
Since the stability of engineering rock masses has important practical significance to projects like mining, tunneling, and petroleum engineering, it is necessary to study mechanical properties and stability prediction methods for rocks, cementing materials that are composed of minerals in all shapes and sizes. Rocks will generate acoustic emission during damage failure processes, which is deemed as an effective means of monitoring the stability of coal rocks. In the meantime, actual mining and roadway surrounding rocks tend to have transverse effects; namely, the transverse scale is larger than the length scale. Therefore, it is important to explore mechanical properties and acoustic emission properties of rocks under transverse size effects. Considering the transverse scale effects of rocks, this paper employs the microparticle flow software PFC2D to explore the influence of different aspect ratios on damage mechanics and acoustic emission properties of rocks. The results show that (1) the transverse scale affects uniaxial compression strength of rocks. As the aspect ratio increases, uniaxial compression strength of rocks decreases initially and later increases, showing a V-shape structure and (2) although it affects the maximum hit rate and the strain range of acoustic emission, it has little influence on the period of occurrence. As the transverse scale increases, both damage degree and damage rate of rocks decrease initially and later increase.
\end{abstract}

\section{Introduction}

Rocks are composed of different sizes and shapes of mineral particles and bound together by certain cementing materials. Under exterior loads, preexisting fissures of rocks will evolve, produce, and develop new fissures constantly, thereby damaging internal rocks and causing macroscopic rupture instability [1]. Since rock mass instability will induce major geotechnical disasters such as tunnel deformation and mine pressure bumping, it is necessary to research rock instability mechanisms and seek suitable means of monitoring rock mass stability. Rock damage and rupture are accompanied by acoustic emission that consecutively monitors microcrack growth and effectively monitors and predicts engineering rock mass stability and rock burst [2-4].

In terms of researches on mechanical properties and acoustic emission properties of rocks, scholars focus on analyzing characteristics [5-10] of rocks with standard scale (diameter $50 * 100 \mathrm{~mm}$ ) under compression, tension, and shearing conditions. Restricted by the test conditions, seldom do scholars study mechanical properties and acoustic emission properties of rocks under scale effects. By virtue of numerical simulation, Document [11] discusses mechanical properties and acoustic emission properties of coal rocks with different aspect ratios, which helps understand relations between compression failure mechanisms and precursory information about acoustic emission. However, actual mining and roadway surrounding rocks tend to have transverse effects; namely, the transverse scale is larger than the length scale. Therefore, it is necessary to explore mechanical properties and acoustic emission properties of rocks under transverse effects. This is of practical significance to the monitoring and prewarning of engineering rock mass stability.

Considering that in situ engineering tests and indoor acoustic emission tests are characterized by high discreteness and great man-made errors, this paper introduces numerical methods to investigate damage mechanics and acoustic emission properties of rocks with different transverse scales. 
Firstly, the paper performs uniaxial compression of rocks by virtue of contact bond models of PFC2D and obtains physicomechanical parameters consistent with indoor tests through the cut-and-try method [12]. Secondly, the paper builds models for rocks with different transverse scales and analyzes their mechanical properties and acoustic emission properties. Finally, the paper analyzes damage evolution features of rocks with different transverse scales on the basis of acoustic emission properties.

\section{Uniaxial Compression PFC Models for Rocks with Different Transverse Scales}

2.1. Particle Flows. Based on the discrete element method, Cundall and Strack [13] proposed particle flow code, a theory that analyzes damage evolution mechanisms and deformations of materials at the microlevel. When simulating bond failures of particles, particle flow code offers two bond modes [14]: contact bond and parallel bond, wherein contact bond, which is appropriate to simulate granular materials like soil masses, refers to bonds between particle points, produces forces only when relative displacement between particles occurs, and cannot carry over moment; parallel bond, which is appropriate to simulate compact materials like rocks, refers to bonds between particle surfaces and carries over moment. This paper utilizes parallel bond models to establish uniaxial compression models for rocks, thereby analyzing the influence of scale effects on acoustic emission properties.

2.2. Physicomechanical Parameters of Rock Specimens. Particle flow theory represents the macroscopic physicomechanical properties of rocks as their microscopic physicomechanical properties. However, the microscopic parameters of rocks do not directly correspond to their macroscopic parameters. The microscopic parameters were checked and corrected prior the numerical simulation of the uniaxial compression model. During this process, a large number of numerical simulation tests were performed as either laboratory or in situ field tests under similar conditions. The numerical simulation results were compared with the laboratory or in situ field test results, and the microscopic parameters were repeatedly adjusted via trial and error method.

2.2.1. Determining the Initial Value of the Physicomechanical Parameters. The mesomechanical parameters of the microparticle flow model mainly include the contact modulus of the particles $E_{c}$, particle normal stiffness and tangential stiffness ratio $k_{n} / k_{s}$, friction coefficient $f$, parallel bond radius multiplier $\lambda$, bond modulus $\bar{E}_{c}$, ratio of the normal stiffness and tangential stiffness of bond $\bar{k}_{n} / \bar{k}_{s}$, and normal and tangential bond strengths $\bar{\sigma}_{c}$ and $\bar{\tau}_{c}$.

The macromechanical parameters (including elastic modulus $E$, Poisson's ratio $\nu$, compressive strength value $\sigma_{c}$, and shear strengths $c$ and $\varphi$ ) of the materials were determined in the indoor test. The preliminary value of particle contact modulus $E_{c}$ and parallel bond modulus $\bar{E}_{c}$ were decided by analyzing the macroscopic mechanical parameters.
TABLE 1: Physicomechanical parameters of granite.

\begin{tabular}{lc}
\hline Parameter & Value \\
\hline Minimum particle size $(\mathrm{mm})$ & 0.3 \\
Particle size ratio & 1.66 \\
Density (kg/m3) & 2800 \\
Contact modulus of the particle (GPa) & 5.0 \\
Deformation of parallel bond modulus (GPa) & 43.0 \\
Normal/tangential stiffness & 3.0 \\
Coefficient of friction & 0.8 \\
Parallel bond normal stiffness (MPa) & $88 \pm 10$ \\
Parallel bond tangential stiffness (MPa) & $160 \pm 10$ \\
\hline
\end{tabular}

The initial particle stiffness value is computed as follows:

$$
\begin{aligned}
& k_{n}=2 t E_{c}, \quad(t=1), \\
& k_{s}=\frac{k_{n}}{\left(k_{n} / k_{s}\right)}, \\
& \bar{R}=\frac{R^{[A]}+R^{[B]}}{2},
\end{aligned}
$$

where $\bar{R}$ is the average radius of all model particles and $R^{[A]}$ and $R^{[B]}$ are the radiuses of two contact particles.

The initial normal and tangential stiffness of the parallel bonding are computed as follows:

$$
\begin{aligned}
& \bar{k}_{n}=\frac{\bar{E}_{c}}{R^{[A]}+R^{[B]}}, \\
& \bar{k}_{s}=\frac{\bar{k}_{n}}{\left(\bar{k}_{n} / \bar{k}_{s}\right)} .
\end{aligned}
$$

2.2.2. Determining the Mesomechanical Properties of Rock. Restricted by indoor test conditions, this paper adopts parameters in Document [15] for numerical tests. The document based on mechanical parameters of triaxial compression tests on granites in an underground crude oil storage cavern in Huangdao National Oil Reserve Base makes repeated adjustment by virtue of the trial and error method and believes that physicomechanical parameters in Table 1 approach to macromechanical parameters of real rocks. After checking, macromechanical parameters of rock specimens under the confining pressure of $6 \mathrm{Mpa}$ are consistent with those of granite specimens. The stressstrain curves of experimental test and numerical test of granite rock mass are shown in Figure 1 and they have a higher similarity. The elastic modulus, Poisson's ratio, and peak strength are $28.7 \mathrm{Gpa}(28.4 \mathrm{Gpa}), 0.2300$ (0.2285), and $130.5 \mathrm{Mpa}(132.8 \mathrm{Mpa})$, respectively. Final failure modes of the specimens, which are consistent with the results of indoor tests, are shown in Figure 2.

2.3. PFC Simulation for Acoustic Simulation. When the bond strength is smaller than the transmission strength between particles, particle bonds shall break and generate microcracks [16]. During the extension of microcracks, the expended 


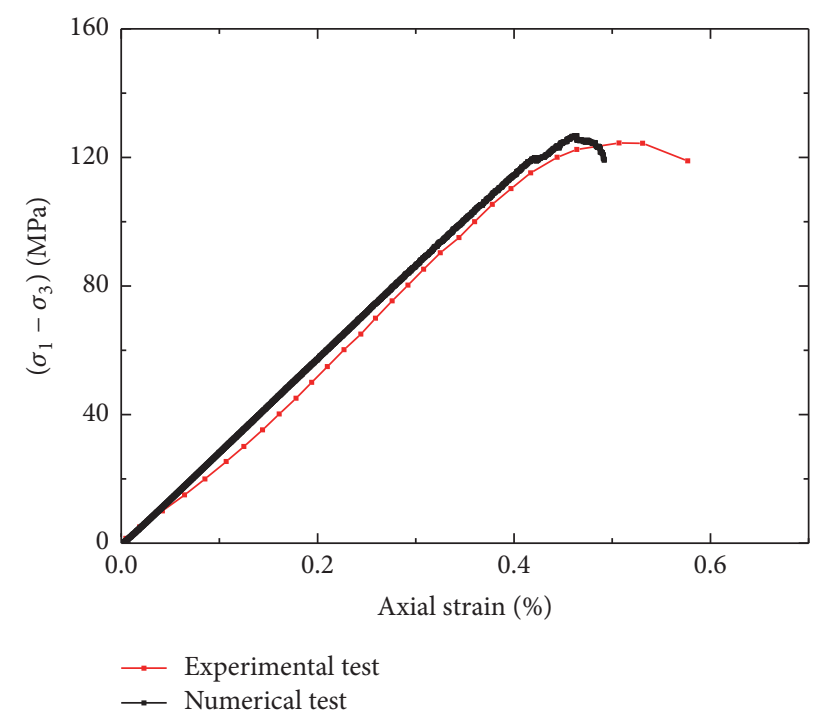

Figure 1: Stress-strain curves of experimental test and numerical test of granite rock mass.

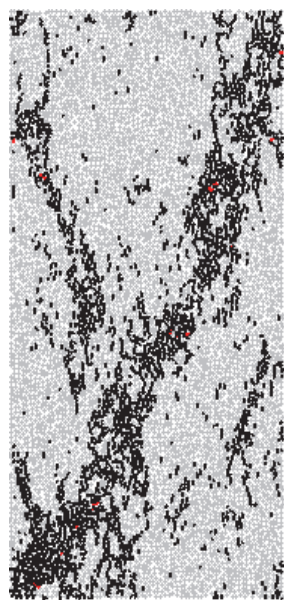

(a) PFC

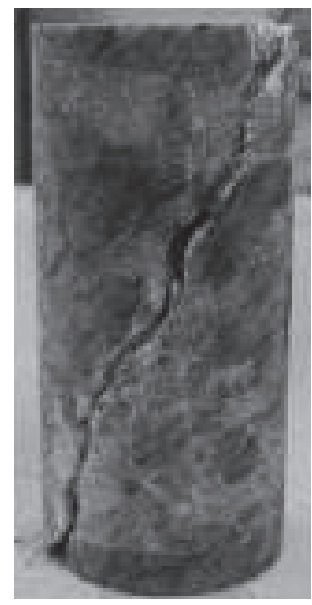

(b) Granite
FIGURE 2: Failure modes of granite in compression at a confining stress of $6 \mathrm{MPa}$.

energy shall be quickly released in the form of acoustic waves, which is referred to as acoustic emission. Therefore, it is feasible to script Fish languages to monitor the broken number of parallel bonds in real time, thereby researching and analyzing damage evolution and acoustic emission properties of rocks.

\subsection{Numerical Models for Uniaxial Compression Rocks with} Different Transverse Scales. To analyze the influence of transverse effects on damage evolution and acoustic emission properties of rocks, specimens with different aspect ratios $(K)$ are adopted; the fixed height is $100 \mathrm{~mm}$ and the $K$ values are $0.5,0.75,1.0,1.25$, and 1.5, respectively, as shown in Figure 3. The paper employs parameters in Table 1 , without considering the influence of particle shapes and particle distribution. By virtue of radius expansion, plenty of particles are generated in the set region to satisfy porosity. The five modes generate 8397, 12596, 16795, 20993, and 25192 particles separately. As for unbalanced forces arising from the generation process, they are cyclically eliminated. The plane stress condition was assumed and the same loading speed (by moving the top wall) of $0.01 \mathrm{~mm} / \mathrm{s}$ was adopted.

\section{Numerical Result Analysis}

3.1. Strength Properties of Rocks with Different Aspect Ratios. Figures 4 and 5 demonstrate stress-strain curves and peak intensity curves of numerical specimens of rocks with different aspect ratios. According to Figure 4, stress-strain curves of rocks in all test programs experience three stages, excluding the compaction stage. The reasons are as follows: microparticles in the particle flow code are incompressible and invariable rigid spheres and connected by bonds, without initial damage. Since there is no compaction stage, elastic modulus of the various programs is almost the same: 28.5 MPa.

According to Figure 4, when the aspect ratio is smaller than 1, uniaxial compression strength of rocks gradually decreases with the increase in aspect ratio. In other words, it is inversely proportional to the aspect ratio, which is consistent with the opinion of Hoek and Brown [17] and Pells [18]. When the aspect ratio is greater than 1 , mechanical loadbearing capacity of numerical specimens gradually increases with the increase in aspect ratio. What is more, the postpeak mechanical properties are more complex. Overall, uniaxial compression strength of rocks initially increases and later decreases with the increase in aspect ratio, showing a Vshaped structure. In addition, there is no corresponding relationship between aspect ratio and changes in the peak intensity. The uniaxial compression strength is $125.73 \mathrm{MPa}$ when $K=0.75$, which is $2.47 \%$ lower than that $(128.92 \mathrm{MPa})$ when $K=0.5$ and $4.47 \%$ higher than that $(120.11 \mathrm{MPa})$ when $K=1$. When $K=1.25$, the uniaxial compression strength of specimens is $123.31 \mathrm{MPa}$, which is $2.66 \%$ lower than that when $K=1$ and $7.36 \%$ higher than that when $K=1.5$.

Figure 6 displays failure modes of numerical specimens of rocks with different aspect ratios. It can be seen from the figure that numerical specimens in different programs have different failure modes. When $K=0.5$, the failure cracks are diagonal; when $K=0.75$, the failure cracks are crossed, with two large cracks; when $K=1.0$, the failure cracks are crossed, with plenty of failure cracks; when $K=1.25$, the failure cracks are V-shaped; when $K=1.5$, the failure cracks are wave shaped.

\subsection{Acoustic Emission Properties of Rocks with Different Aspect} Ratios. Figures 7 and 8 show AE characteristic curves and time-series curves of numerical specimens of rocks with different aspect ratios, respectively. According to Figure 7, acoustic emission properties of rocks with different transverse scales are as follows: (1) in the elastic stage, the number of AE hits gradually increases. Since the models fail to fully embody the compaction stage, there is no AE hit in the initial phases, which is different from acoustic emission tests of 


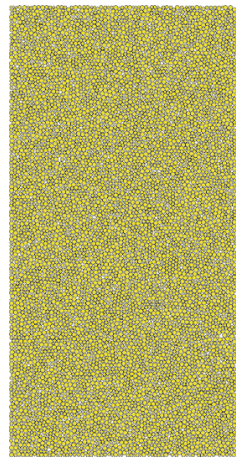

$K=0.5$

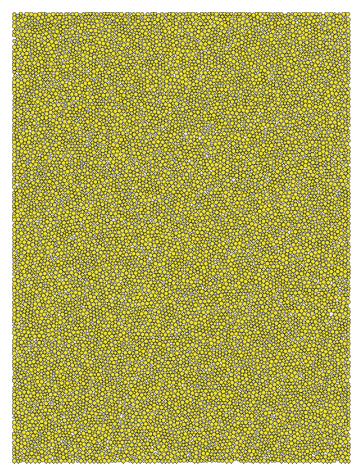

$K=0.75$

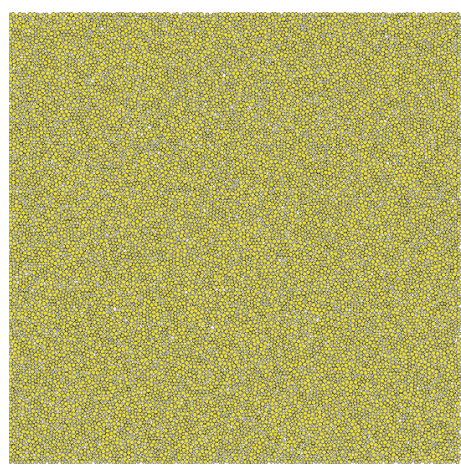

$K=1.0$

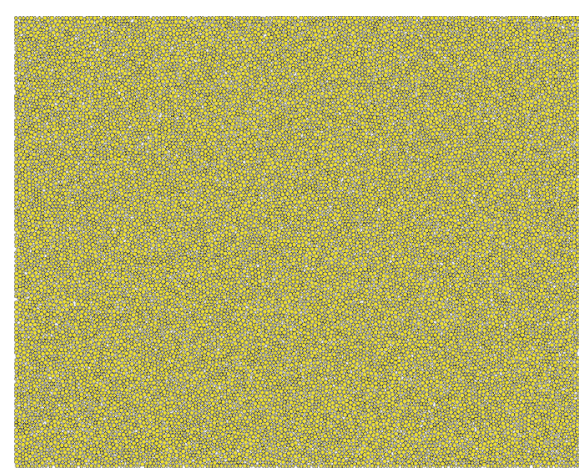

$K=1.25$

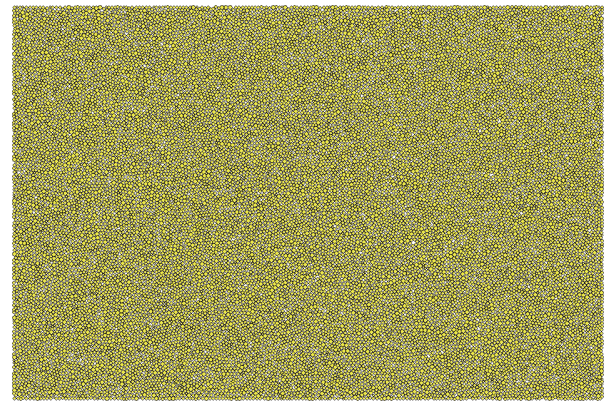

$K=1.5$

FIGURE 3: Numerical specimens of rocks with different aspect ratios.

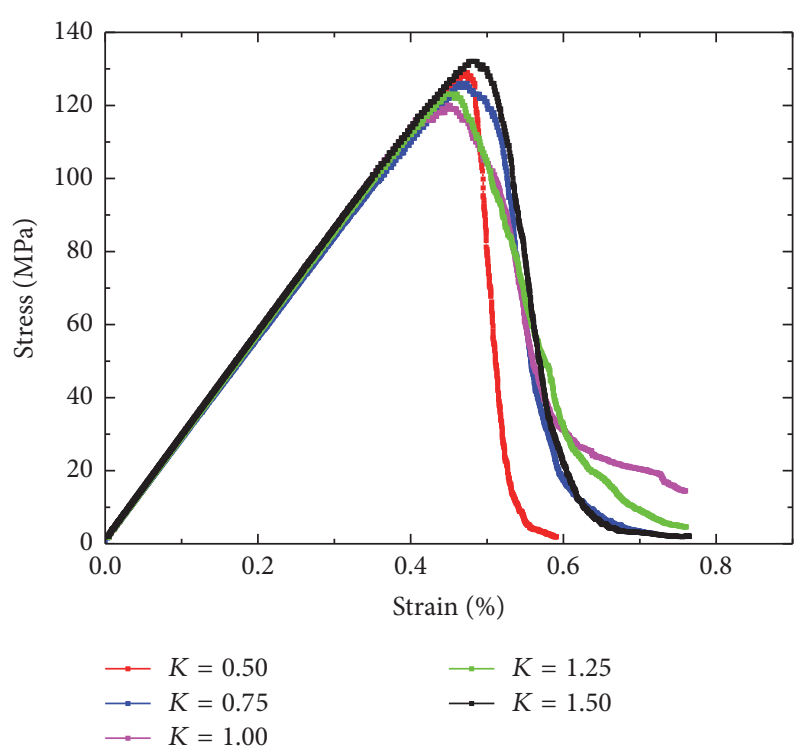

FIGURE 4: Stress-strain curves of numerical specimen of rocks with different aspect ratios.

real rocks. Due to inner pores, crack closure, and friction, real rocks are always accompanied by acoustic emission in the contraction stage. (2) In the plastic stage when rocks are stable, rocks will generate plenty of acoustic emission signals and inner cracks will evolve constantly. When the damage reaches a certain extent, rocks will be damaged and generate more postpeak acoustic emission signals. (3) In the failure

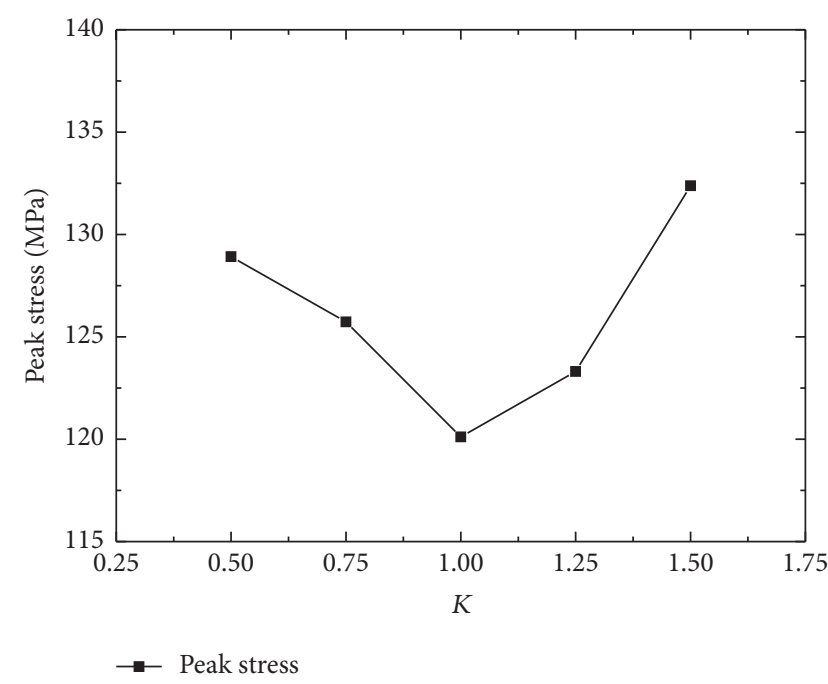

FIGURE 5: Peak intensity curves of numerical specimen of rocks with different aspect ratios.

stage, rock specimens still have certain load-bearing capacity, inner cracks further expand, and hit signals decrease rapidly, occasionally accompanied by sudden changes (e.g., when $K=$ 0.75 or $K=1.0$ ).

In the meantime, the influence of transverse effects on acoustic emission is described as follows: (1) influence the maximum hit rate. The maximum hit rate increases with the increase in transverse scale. When $K=0.5 / 0.75 / 1 / 1.25 / 1.5$, the maximum hit rate is 30/32/33/37/42 times/step. (2) Influence 


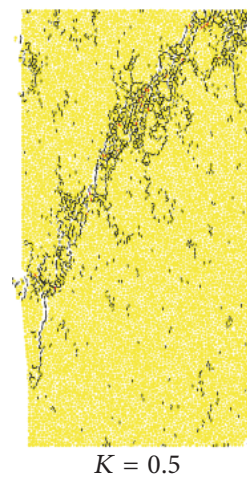

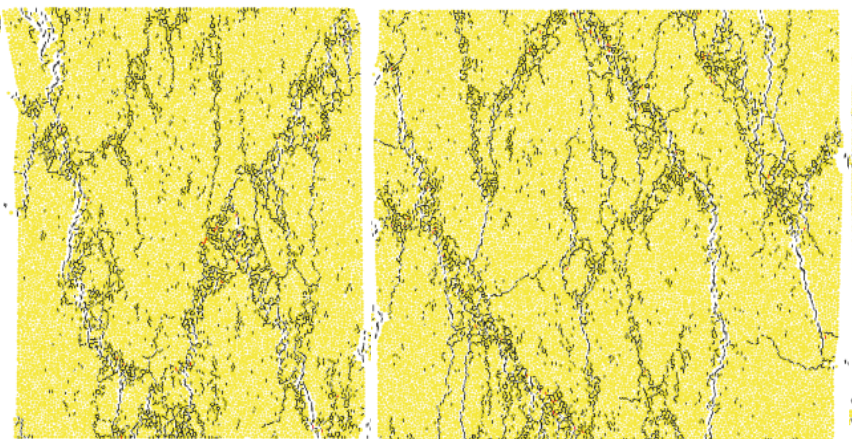

$K=0.75$
$K=1.0$

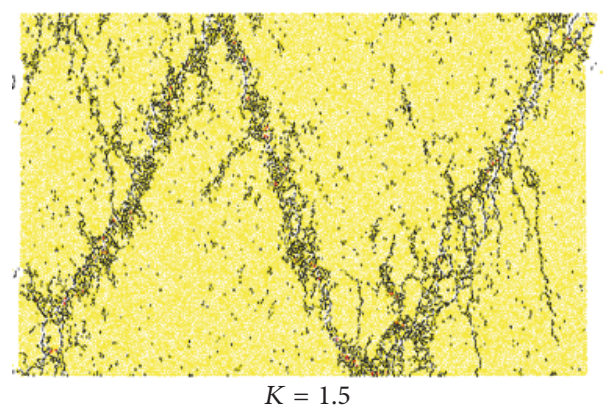

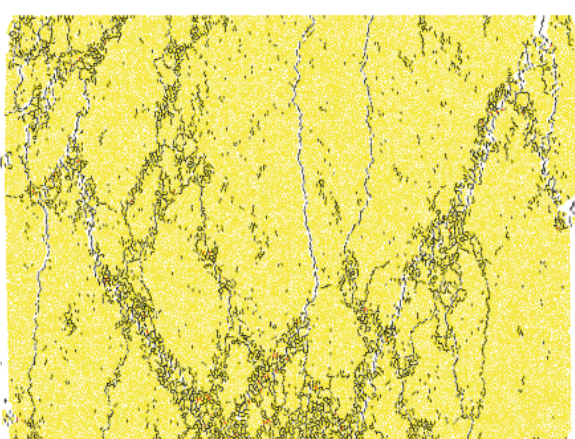

$K=1.25$ 

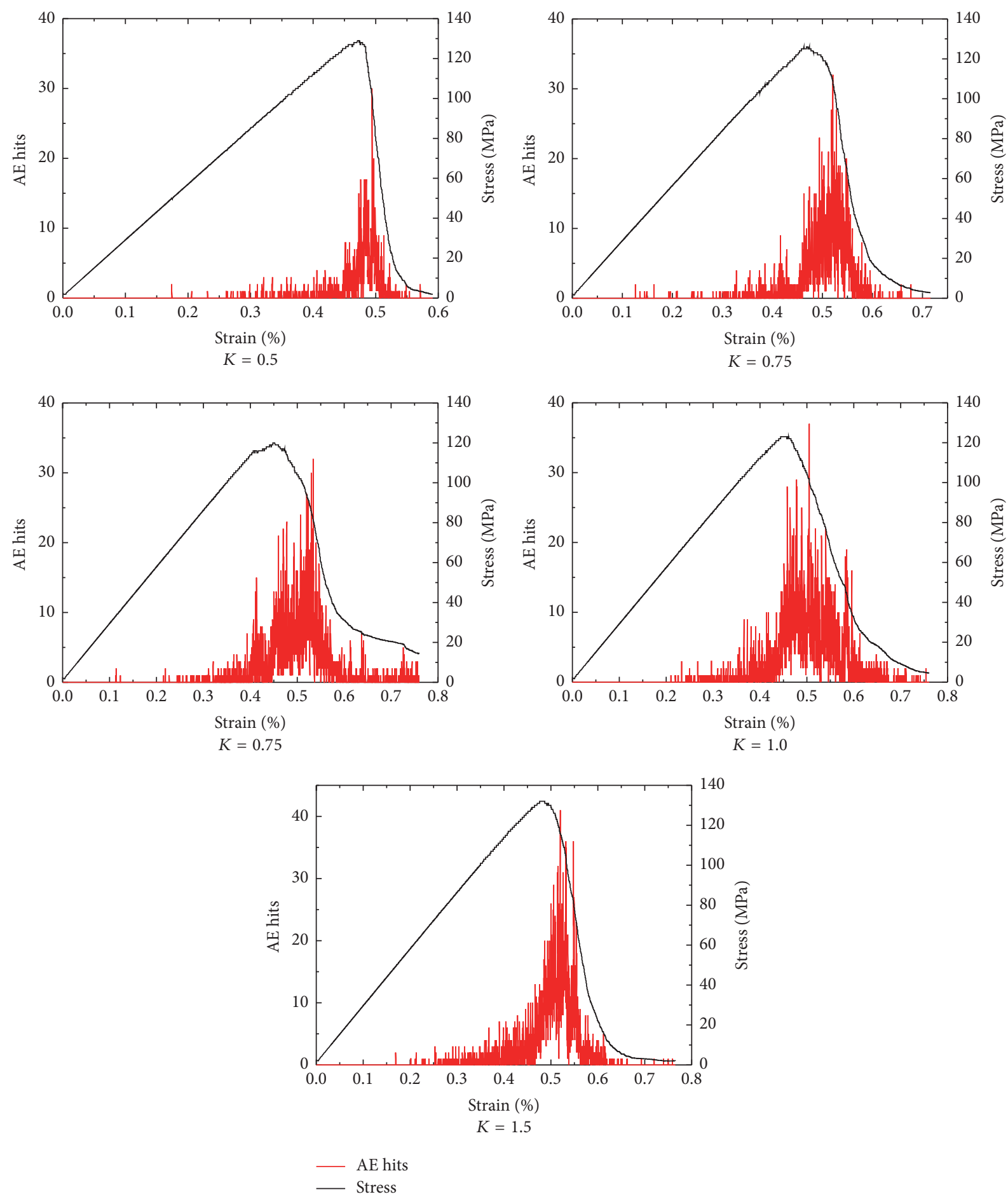

FIGURE 7: Stress-strain-AE characteristic curves of numerical specimens of rocks with different aspect ratios.

4.2. Damage Evolution Properties of Rocks with Different Transverse Scales. Figure 9 displays damage variable-strain curves of numerical specimens of rocks with different aspect ratios. According to the figure, the curves flatten in the elastic stage, which indicates that the damage degree and damage rate are small; in the elastic stage when rocks are stable, small cracks in coal rocks quickly develop into joint fissures, thereby macroscopically damaging the specimens and dramatically increasing the damage degree and damage rate; in the damage phase, the damage degree reaches the maximum while the damage degree and damage rate gradually level off.

Transverse effects have a little impact in the elastic stage and make a big difference in the plastic stage and the failure stage. In the elastic stage, the damage degree is small and 


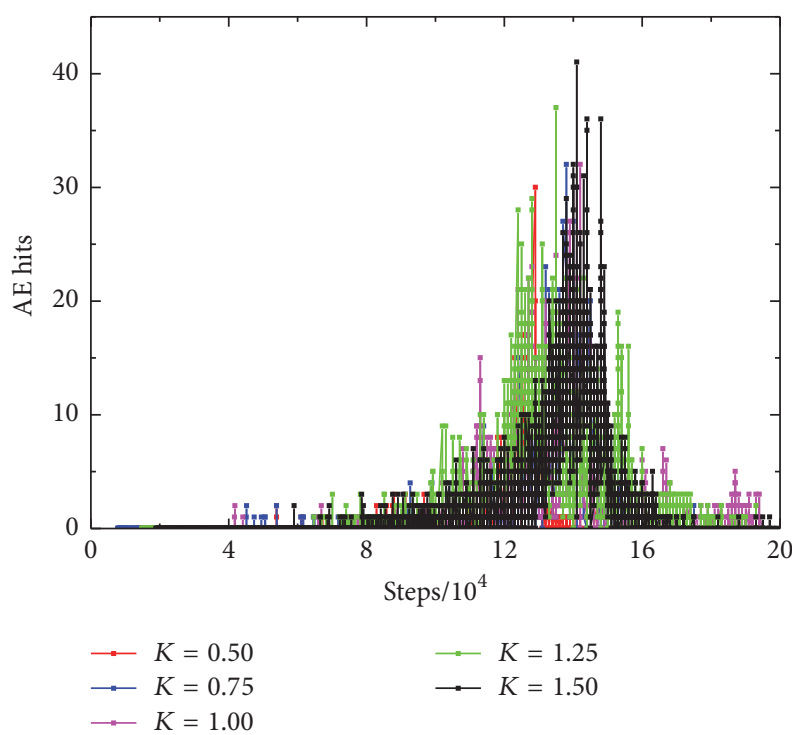

FIGURE 8: AE time-series curves of numerical specimens of rocks with different aspect ratios.

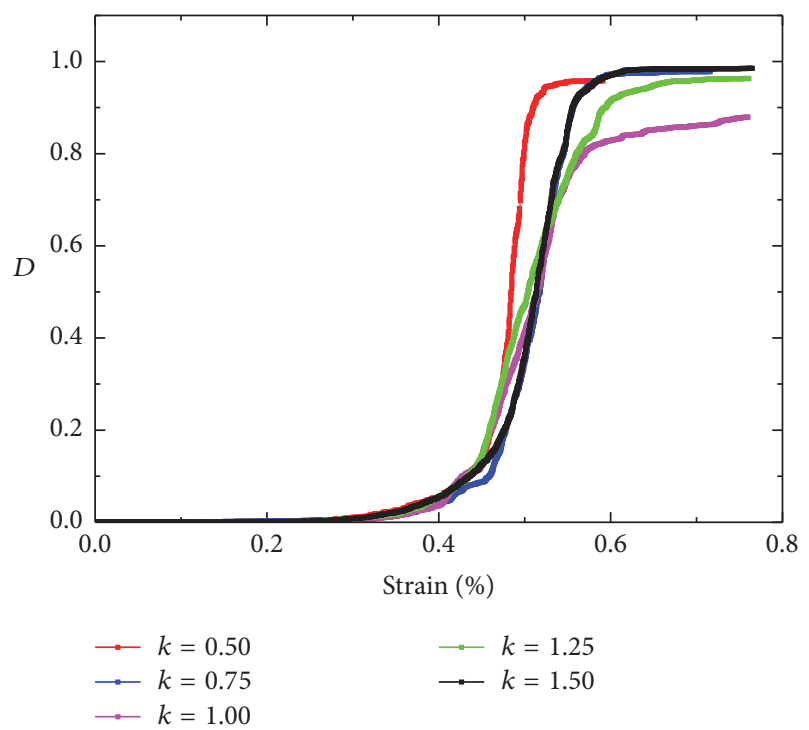

FIGURE 9: Damage variable-strain curves of numerical specimens of rocks with different aspect ratios.

the rocks are integral, regardless of the transverse scale. In the plastic stage, the damage degree and damage rate initially decrease and later increase with the increase in transverse scale, which is similar to the influence on uniaxial compression strength. In the failure stage, since rocks are instable and discrete, transverse effects do not obviously influence damage evolution properties of rocks. Nevertheless, it approximately presents the following trends: initially decrease and later increase.

\section{Conclusion}

As the aspect ratio increases, uniaxial compression strength of rocks decreases initially and later increases, showing a
V-shaped structure. What is more, there is no corresponding relation between aspect ratio and changes in peak intensity.

The influence of transverse effects on acoustic emission properties is mainly described as follows: as the transverse scale increases, the maximum hit rate and the strain range of acoustic emission increase accordingly. However, it has little influence on the period of occurrence.

Transverse effects have a small impact in the elastic stage and make a big difference in the plastic stage and the failure stage. As the transverse scale increases, both damage degree and damage rate of rocks decrease initially and later increase.

It is very important to know that this research was based on numerical tests; the research result may have a gap between the real rock of real scale, so the research results are not suitable for direct application in engineering.

\section{Conflicts of Interest}

The authors declare that they have no conflicts of interest.

\section{Acknowledgments}

The authors thank the Enterprise Foundation "Experiment Research of Drill Fluid on Rock Mechanics Parameters of Coal and Methods Optimization of Borehole Stabilization Using Chemical Approach" (Item no. HX20150421) for contributions to this paper.

\section{References}

[1] C. D. Su and Z. H. Zhang, "Analysis of plastic deformation and energy property of marble under pseudo-triaxial compression," Chinese Journal of Rock Mechanics and Engineering, vol. 27, no. 2, pp. 273-280, 2008.

[2] W. Blake, Microseismic Application for Mining: A Practical Guide, Bureau of Mines, Washington, DC, USA, 1982.

[3] D. A. Lockner, J. D. Byerlee, V. Kuksenko, A. Ponomarev, and A. Sidorin, "Quasi-static fault growth and shear fracture energy in granite," Nature, vol. 350, no. 6313, pp. 39-42, 1991.

[4] Z. J. Wen, X. Wang, and Q. H. Li, "Simulation analysis on the strength and acoustic emission characteristics of jointed rock mass," Technical Gazette, vol. 23, no. 5, pp. 1277-1284, 2016.

[5] V. L. Shkuratnik, Y. L. Filimonov, and S. V. Kuchurin, "Regularities of acoustic emission in coal samples under triaxial compression," Journal of Mining Science, vol. 41, no. 1, pp. 44$52,2005$.

[6] I. Iturrioz, G. Lacidogna, and A. Carpinteri, "Acoustic emission detection in concrete specimens: experimental analysis and lattice model simulations," International Journal of Damage Mechanics, vol. 23, no. 3, pp. 327-358, 2014.

[7] S. Li, X. Yin, Y. Wang, and H. Tang, "Studies on acoustic emission characteristics of uniaxial compressive rock failure," Chinese Journal of Rock Mechanics and Engineering, vol. 23, no. 15, pp. 2499-2503, 2004.

[8] B. Gao, L. Huigui, S. Yu et al., "Triaxial compressed coal kind of acoustic emission and fractal feature," Mechanics and Practice, vol. 35, no. 6, pp. 49-54, 2013.

[9] S. Wu, S. Zhang, and D. Shen, "Experimental study on Kaiser effect of acoustic emission in concrete under uniaxial tension 
loading," China Civil Engineering Journal, vol. 41, no. 4, pp. 3139, 2008.

[10] J. Xu, H. Wu, L. Lu, H. Yang, and H. Tan, "Experimental study of acoustic emission characteristics during shearing process of sandstone under different water contents," Chinese Journal of Rock Mechanics and Engineering, vol. 31, no. 5, pp. 914-920, 2012.

[11] Z. Wen, X. Wang, L. Chen, G. Lin, and H. Zhang, "Size effect on acoustic emission characteristics of coal-rock damage evolution," Advances in Materials Science and Engineering, vol. 2017, Article ID 3472485, 8 pages, 2017.

[12] Itasca Consulting Group Inc., Manual of Particle Flow Code in 2-Dimension (Version 3.10), Itasca Consulting Group Inc., Minneapolis, Minn, USA, 2005.

[13] P. A. Cundall and O. D. Strack, "A discreate numerical model for granula assemblies," Geotechnique, vol. 29, no. 1, pp. 47-65, 1979.

[14] Itasca Consulting Group, PFC2D (Particle Flow Code in 2 Dimensions) Fish in PFC2D, Itasca Consulting Group, Minneapolis, Minn, USA, 2008.

[15] Z. Xuepeng, W. Gang, J. Yujing et al., "Simulation research on granite compression test based on particle discrete element model," Rock \& Soil Mechanics, vol. 35, suppl. 1, pp. 99-105, 2014.

[16] J. F. Hazzard, R. P. Young, and S. C. Maxwell, "Micromechanical modeling of cracking and failure in brittle rocks," Journal of Geophysical Research: Solid Earth, vol. 105, no. 7, pp. 1668316697, 2000.

[17] E. Hoek and E. T. Brown, Underground Excavations in Rock, vol. 2, London Institute Mining and Metallurgy, London, UK, 1980.

[18] P. J. N. Pells, Uniaxial Strength Testing, Comprehensive Rock Engineering Principles, Practice \& Projrcts, Pergamon Press, Oxford, UK, 1993.

[19] X. Liu, J. Lin, and Z. Yuan, "Rrsearch on evaluation of material fatigue damage by acoustic emission technology," China Railway Science, vol. 18, no. 4, pp. 74-91, 1997.

[20] L. M. Kachanov, "Time rupture process under creep conditions," Izvestia Akademii Nauk SSSR, Otdelenie Tekhnicheskich Nauk, vol. 8, pp. 26-31, 1958.

[21] B. X. Liu, J. L. Huang, Z. Y. Wang, and L. Liu, "Study on damage evolution and acoustic emission character of coal-rock under uniaxial compression," Chinese Journal of Rock Mechanics and Engineering, vol. 28, suppl. 1, pp. 3234-3238, 2009. 


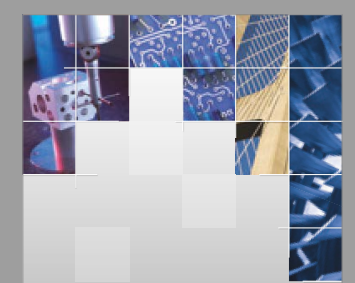

\section{Enfincering}
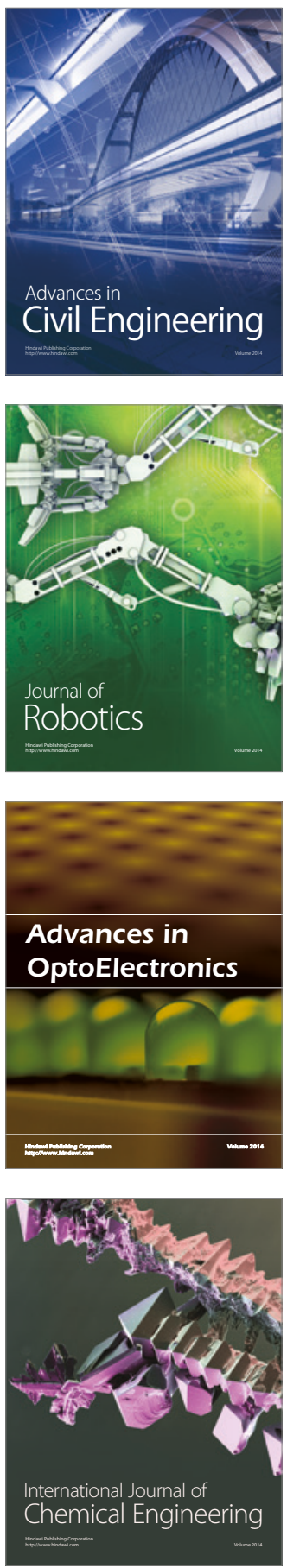

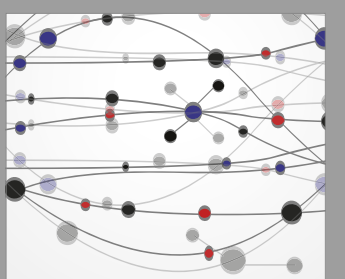

The Scientific World Journal

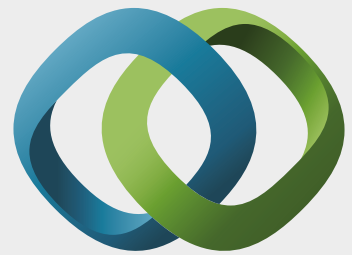

\section{Hindawi}

Submit your manuscripts at

https://www.hindawi.com
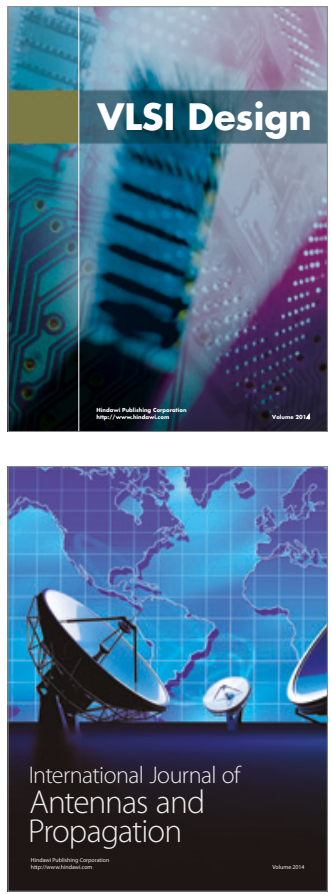

\section{Rotating}

Machinery
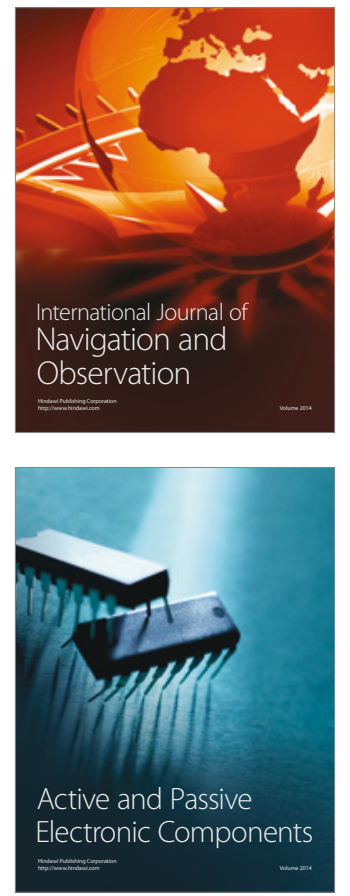
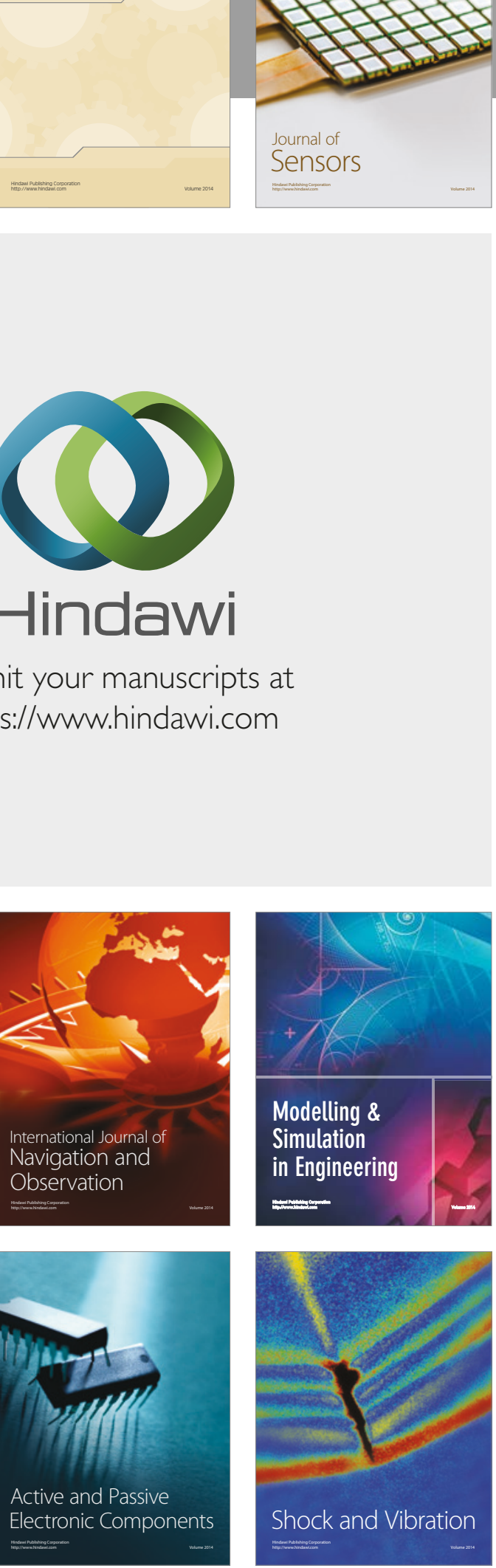
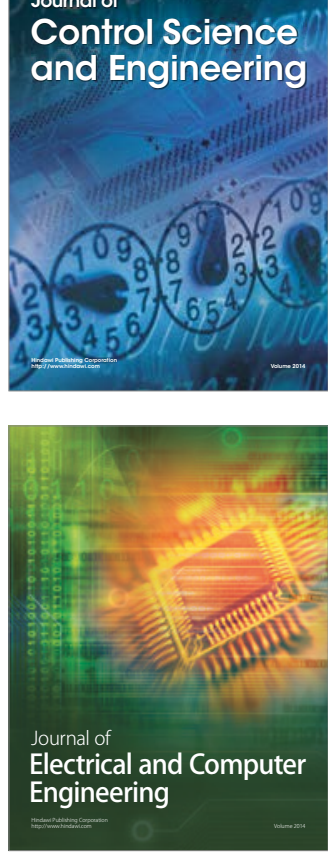

Distributed

Journal of

Control Science

and Engineering
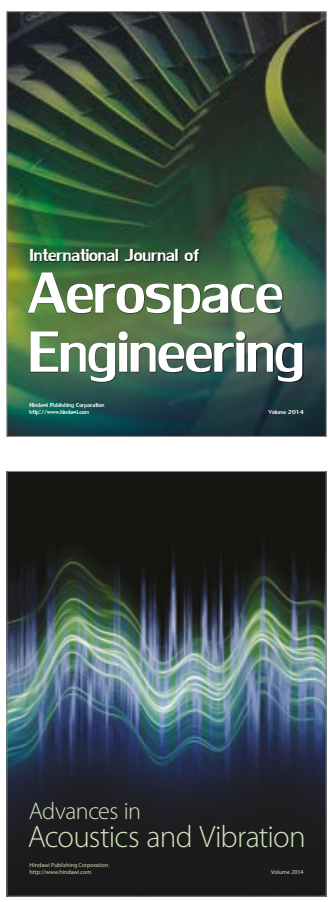

Sensor Networks 